\title{
Construction Management of a High Rise Structure Using MSP Software
}

\author{
Mr. Affan Shaikh ${ }^{1}$, Mr. Om Sankhe ${ }^{2}$, Mr. Shafahad Ansari ${ }^{3}$, Mr. Chirag Sankhe ${ }^{4}$, \\ Mrs. Mitali Shelke ${ }^{5}$ \\ ${ }^{1234}$ UG Students, Department of Civil Engineering, St John College of Engineering \& Management, Palghar \\ ${ }^{5}$ Assistant Professor, Department of Civil Engineering, St John College of Engineering \& Management, Palghar
}

Received on: 03 May, 2021, Revised on: 30 May, 2021, $\quad$ Published on: 31 May, 2021

\begin{abstract}
High-rise residential building is a type of housing that has multi-dwelling units built on the same land. The exploding population, largely urban, creates an increasing demand for tall buildings. The ever increasing population and growing economies in major cities of the world mean increasing urbanization globally and the continuing rise in population density in urban areas. The tall building can accommodate many more people on a smaller land than would be the case with low-rise building on the same land. In our project we have mainly worked on the construction management of high rise structure. The scheduling of various activities has been done in Microsoft Project Management Software by adding various activities, duration, resources required and cost of each activities. The various difficulties faced during the entire project was also identified and solved.
\end{abstract}

Keywords-Scheduling, multi dwelling, construction management, project management software

\section{I- INTRODUCTION}

T he future of India is what Indians are building today, and the Indian goals along with other means and resources will allow the nation to determine the future of the country. India has suffered greatly in recent decades as a result of occupation, closure and lack of resources.
That and other issues have caused stagnation in many aspects of civilization and progress for the Indian society in future. Despite this, commercial and residential construction work in India is increasing rapidly to meet the growing needs of the population and to keep up with global development. For India to progress in terms of construction project construction must be studied carefully and prepared well in order to get the best results, and to help in moving in the right direction to establish the future goals. The requirements of growing population in Mumbai are growing at rapid rate with the rate of population. People are searching for more space for their enhancing lifestyles. It is self explanatory that accommodation is one of the basic requirements for any industry or a person personally. In this case to achieve the demands of people the high rise buildings are the major solution both aesthetically, and technically. The lack of risk assessment from the perspective of project management is one of the key contributors to the problem. To take an example, Palais royal located in Lower Parel, Mumbai is on hold due to lack of risk assessment and management before starting the construction. High rise buildings are one of the top most sophisticated structures in demand today. Normally each and every construction companies today are working on it. India lack the technologies for high rise project because of short construction history and insufficient 


\section{International Journal of Innovations in Engineering and Science, www.ijies.net}

data and research. With the introduction of RERA Act in 2016 it has brought much needed efficiency and transparency in the construction industry via uniform regulation. With RERA Act implemented across the country, Developers are likely to focus on the Timely delivery of their ongoing projects and also remain increasingly flexible on payments. Thus with the introduction of RERA Act Construction Management has became much more vital and inevitable in the country.

\section{II- METHODOLOGY}

- Determination of objective

- Determination of scope of study

- Study of Literature review

- Conducting Site Visits

- Understanding of Microsoft project software

- Preparation of cost estimates, budget

- Resource management

- Implementation of software

- Conclusion

\section{III- MSP SOFTWARE}

- Microsoft project is a project management software product, developed and sold by Microsoft. it is designed to assist a project manager in developing a schedule, assigning resources to tasks, tracking progress, managing the budget, and analyzing workloads.

- The scheduling of the entire project has been done in MSP software

- All the activities, duration, resources, cost have been added in the software.

The following is the Work breakdown structure adopted:

- Site clearance

- Centre-line marking

- Construction of Footings

- Backfilling

- $\quad$ Plinth Beam

- Column marking and starters

- Column R/F tying

- Column Casting

- Formwork for beam and slab

- Laying reinforcement for slab and beams

- Electric layout installation

- Slab and beam casting

- Brickwork

- Internal waterproofing

- Internal plastering
- External plastering

- Internal plumbing work

- $\quad$ Flooring work

- Internal electric work

- Internal and external painting

- External plumbing work

- $\quad$ Facade work

The image below indicate the activities along with Gantt chart:

\begin{tabular}{|c|c|c|c|c|c|c|c|}
\hline$\theta$ & $\begin{array}{l}\text { Tad } \\
\text { Mode . }\end{array}$ & Tablliame & - Durbion . & - Start & - Frich & - Buefne Sat. & - Eaceline Fisit. \\
\hline & 5 & $\begin{array}{l}\text { ¿ARIANA } \\
\text { RESIDENCY }\end{array}$ & 393 days & $\operatorname{Aen} 20,105 / 2 a$ & Tua13/s/22 & Hon $07 / 10,19$ & $\mathrm{HA}$ \\
\hline$V$ & 5 & Exavation & 71.35 dap & Hen $20,05 / 2$ & Thung/ts/20 & Hon $2,106 / 20$ & Thuoshap/a \\
\hline$V$ & 5 & GFstab & 1725 dap & Frict, to, 20 & Sat 15, & Friathy & Sattighs/20 \\
\hline$V$ & 5 & 1stskb & 1725 dap & Hen $21 / 2 / 2$ & Tue Os/11/20 & Hon 21, ho/20 & Tteob/10/2a \\
\hline$V$ & 5 & 2nd slab & 17 deas & Wed $n / 1,1 / 20$ & Tha $2 / 11 / 20$ & Wedor/to/,a & Thu $22 / 10 / 2 \mathrm{a}$ \\
\hline$V$ & 5 & 3nd 5leb & 1725 dap & Fí29/10/20 & Setoo/11/bo & Fri23hila & Satm/11/20 \\
\hline$V$ & 5 & 4th 5leb & 1725 dap & Hen $08 / 11 / 2 a$ & I Tue 24/11/20 & Hon $65 / 11 / 20$ & Tte $24,11 / 2 \mathrm{a}$ \\
\hline$V$ & 5 & 5th sab & $13.5 \mathrm{dap}$ & Wed 25/11/20 & Fil1/12/20 & Wed $25 / 11 / 2 a$ & Fri11/2/2a \\
\hline$V$ & 5 & that dab & 24.35 dap & Fri11/12/30 & setophathe & Fri11/12/20 & $\operatorname{Hon} 28 / 12 / 20$ \\
\hline$V$ & 5 & Thth 5 kb & 225 dap & Hen 04,121/21 & Sat2, & Tue $2 / 12 / 20$ & Thu14,121/21 \\
\hline$V$ & 5 & sth 5leb & $19 J 5 \mathrm{dap}$ & $\operatorname{Asn} 25,11 / 21$ & Thull, to/21 & Hon 11/01/21 & Thu $28,14 / 21$ \\
\hline$V$ & 5 & sth 5lkb & 1725 dap & Fiziplehen & Han 15/03/2 & Frizg/la & sat13/10/21 \\
\hline$V$ & 5 & 1lthslab & 1725 dap & Tue 1fijte/21 & 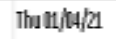 & Han 15/,e/21 & Treoliz/21 \\
\hline$V$ & 5 & 11thslab & 1725 dap & setco,bu/21 & Wed $21 / 4 / 21$ & Wed 0B/17//21 & Fri19/3/2 \\
\hline$V$ & 5 & 12th Slab & $1725 \mathrm{~d} d \%$ & Tha $2, j / 04 / 21$ & setcolos/21 & Satzajos/21 & Wedor/bu/21 \\
\hline & 5 & 13thslab & 1725 dap & Hen $10, / 5 / 21$ & The $27,15 / 21$ & Thu03/4/21 & Hon $25 ; x+21$ \\
\hline & 5 & 1th Sleb & 1725 dzp & Fíza,ks,he1 & Sat12,06/21 & Tve27/h//a & Fri14h/5/4 \\
\hline & 5 & 15th Slab & 1725 dap & Hen14,05/21 & Tue $28 / 6 / 21$ & Han 17/65/21 & Wedco,jos/21 \\
\hline & 5 & 1fth Sleb & 1725 dap & Wed 30/tit/21 & I Thu15/07/24 & Thu03/6/21 & Fri18/js/2 \\
\hline & 5 & 17th Slab & 1725 dap & Fril1; 00 h1 & Hancepoing & Sateg/te/21 & Hon $15 / 00 / 21$ \\
\hline & 5 & 1fth Skb & 1725 dzp & Tue lajter/21 & Frizajtepla & Tue $06 / 7 / 2 / 4$ & Thu $2,[3 / 21$ \\
\hline
\end{tabular}

Fig 1-Activities

\begin{tabular}{|c|c|c|c|c|c|c|c|}
\hline$\checkmark$ & 5 & 17thstb & 225 dep & 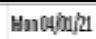 & setzos/1/2 & 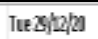 & 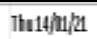 \\
\hline$\checkmark$ & 5 & / Ithstab & 19.5 dep & Hnza/u/p1 & Thulliog/ed & Hont1/4t/3/2 & Thoxinter \\
\hline$\checkmark$ & 5 & sta stab & 1725 dep & Fixflety & 目n15/0/21 & Frizploper & sationeten \\
\hline$\checkmark$ & F & ) 10th Sta & 1725 dep & Toe15iog/21 & 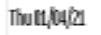 & Hon 15,plefe & 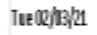 \\
\hline$\checkmark$ & 5 & ) 11thsth & 1725 dep & setrifula & 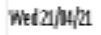 & Wadespiper & Friplopila \\
\hline$\checkmark$ & 5 & 120th Sth & 1725 dep & 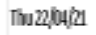 & seto/y/z) & stapold & Wed nillow/2] \\
\hline & 5 & 13th Sab & 1725 dep & Han11/6/21 & Thu 27, istige & Thex/4, 21 & Heodileth \\
\hline & Eq & ) 19h Stab & 1725 dep & Fix/s/y & 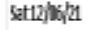 & 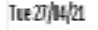 & Fristosita \\
\hline & 5 & IStShab & 175 dep & Hn14/6/21 & 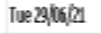 & Hon:17/5/3/4 & Wad C, itofled \\
\hline & 5 & Istisab & 1725 dep & Wed xiphla & Thusisoly & The Byothen & Frisstofled \\
\hline & 5 & Inth stab & 1725 dep & Filffip/h & Hencolopen & stiphoth & Hen Eqhiph \\
\hline & 5 & I3th Sab & 172 dep & 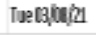 & Fianoles & Texofinh & Thu2ym/2 \\
\hline & 5 & I 12th Sab & 1725 dep & 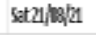 & Hnc6/6os/21 & Fizsiogly & satripaly \\
\hline & 5 & athisab & 1725 dep & 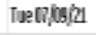 & 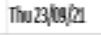 & Hon B, b/a & Thexilach \\
\hline & 5 & zatskb & 1725 dep & Fiz/mpla & Hn11/10/21 & Fizzipald & Hoo 1:3ep/a \\
\hline & 5 & 2andsab & 1725 dep & Тме 12/1) & Fixplaper & 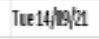 & Wad 2a,iog/21 \\
\hline & 5 & Zadd dab & 1725 dep & setxylapen & Tuessilital & The $x / 2, p$ & Frishingly \\
\hline & 5 & Intenal Friting & 507.5 dep & Thunlation & Tuesiloging & Na & $\mathrm{BA}$ \\
\hline
\end{tabular}

Fig 2-Activities 


\section{International Journal of Innovations in Engineering and Science, www.ijies.net}

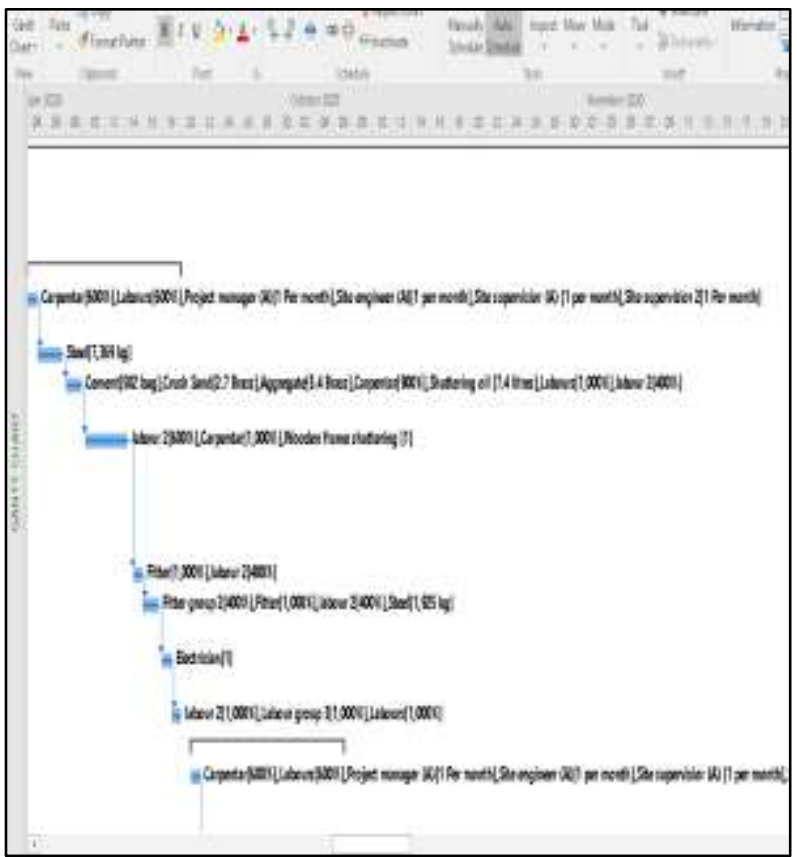

Fig 3- Gantt chart

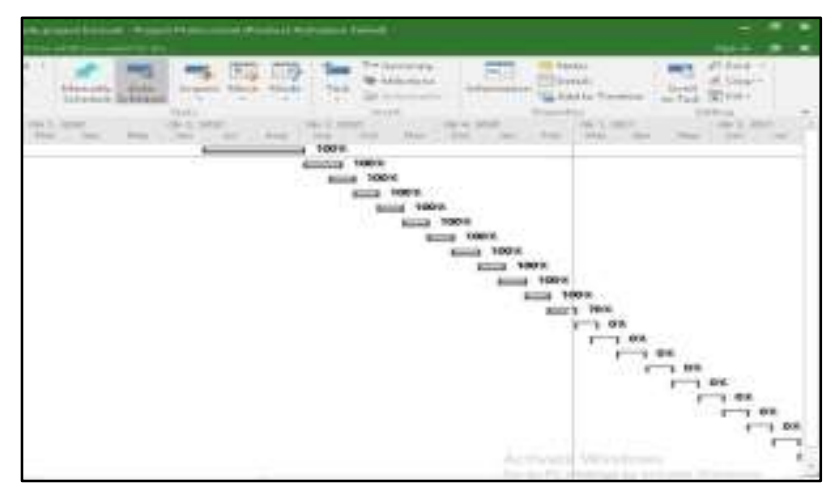

Fig 4- Tracking Gantt

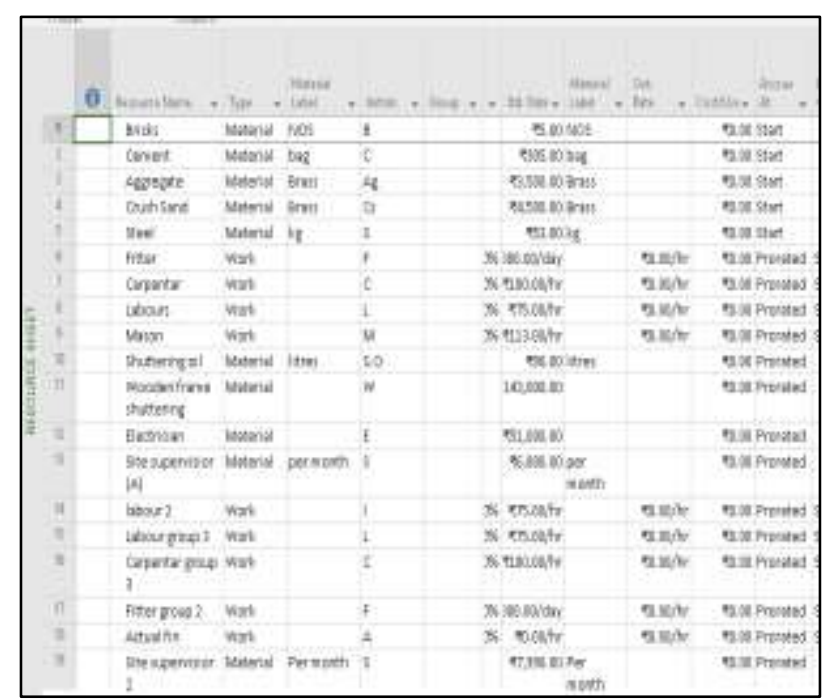

Fig 5-Resources

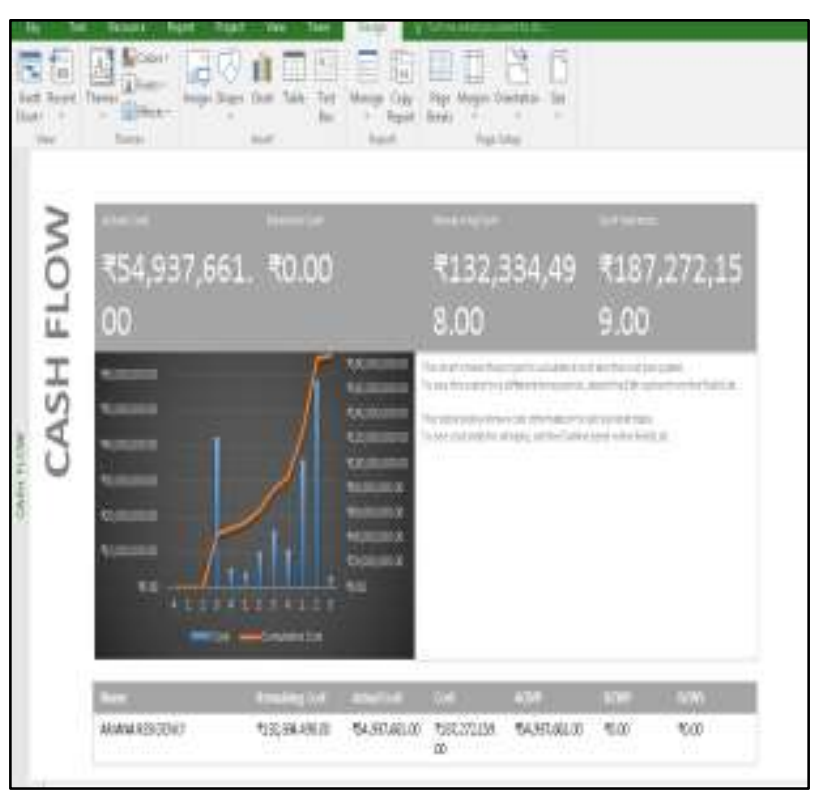

Fig 6- Cost overview

\section{IV- DIFFICULTIES ARISE DURING THE COURSE OF THE PROJECT}

- Climatic conditions

- Covid-19 restrictions

- Delay in legal documents

- Conflict between labour and contractor

- Shortage in construction materials

- Differentiating materials according to their units in resource sheet.

\section{V-RESULT}

The challenges faced during the project and the effect of those challenges on the activities and thereon on the project are studies. After the various activities were added in the software the GANTT CHART was obtained. The interdependencies amongst various activities are shown in the Gantt chart. Also the total approximate cost incurred for the project is also shown in software.

\section{VI- CONCLUSION}

- Accurate and efficient planning and scheduling was done on MSP software made easy working and better results with quick improvisation of corrections and solving problems.

- On the basis of assumptions of the future challenges or difficulties, corrective action were shown in the software like lagging of activities. 
Vol. 6, No. 5, 2021, PP. 01 - 04

\section{International Journal of Innovations in Engineering and Science, www.ijies.net}

- When the activities were added in the software, we could understand the different areas of MSP software to gain in depth knowledge of software.

- In the course of the project we were able to gain knowledge of ongoing activities by visiting on site of Ariana residency (Borivali) and the procedure of construction activities were obtained and studied with respect to time, material and cost ac further those activities were put in MSP software along with duration and cost.

- Overall, the entire project work was very informative and we gathered much more information about the ongoing project and understood various factors which play vital role in such type of projects.

\section{REFERENCES}

[1] Construction engineering and management, $\mathrm{Dr} S$. Seetharaman.

[2] Bhuvanesh Gawad, "Concrete Mix Proportioning: A Short Note", Journal of Environmental Science, Computer Science and Engineering \& Technology 5(3): June 2016, Pages 262-266.

[3] Challenges of construction of high rise building in India, Nanadkumar Chavan.

[4] Role of construction manager in high rise building (0-kyung kwon)
[5] Bhuvanesh Gawad, Swati Dhurve, "Strutural Assessment of old Building", Journal of Environmental Science, Computer Science and Engineering \& Technology 6(4): September 2017, Pages 466-478.

[6] Planning and scheduling of multistory building using MSP, Pooja Tripathi.

[7] Construction techniques and demand of high rise building in India, Dharma Raj.

[8] Bhuvanesh Gawad, Swati Dhurve, "Health Safety and Risk Management in Residential Building", International Journal for Scientific Research \& Development, Volume 8, Issue 12, 2021, Pages 101106.

[9] High rise building, Wikipedia.

[10] Bhuvanesh Gawad, Swati Dhurve, "Planning and designing of Soil Biotechnology Plant for the locality”, International Journal of Innovative Research in science, Engineering and Technology Volume 9, 05 May 2020, Pages 3409-3415.

[11] Planning and scheduling of $G+3$ building (S.Rajkumar)

[12] Bhuvanesh Gawad, Swati Dhurve, Hitesh Vanmali, Mayuresh Patil, "Study of Soil Biotechnology for Waste Water Treatment" SSRG International Journal of Civil Engineering 7.3 (2020): 8-12.

[13] Architectural engineering thesis, Jonathan fisher. 